\title{
A foray into not-quite companion species: design experiments with urban animals as significant others
}

\author{
Li Jönsson \& Tau Ulv Lenskjold, \\ Royal Danish Academy of Fine Arts, School of Design
}

\begin{abstract}
This paper examines the project Urban Animals and Us as a journey - or foray-into the terrain vague between people and (other) animals with whom we share urban space. Through three design experiments developed around speculative prototypes and co-design tools, we attempt to bring "wild" urban animals like magpies and gulls into contact with the residents of a senior retirement home, to explore what new practices can arise between otherwise unconnected life-worlds. We expand the notion of companion species from philosopher of science Donna Haraway and begin to position the current project within a growing interest in animals in contemporary design research. Through analysis of the design experiments and the subsequent discussion, we argue that a foray into interspecies relations can inform the practical research agenda and help to re-articulate the dominant anthropocentricity of design research.
\end{abstract}

KEYWORDS: urban ecologies, co-design experimentation, material speculation, de-anthropomorfication

\section{INTRODUCTION}

Recently, domesticated animals like sheep, dogs, and pigs seem to be enjoying new attention from several anthropologists and design researchers around the world (Mancini, 2011; Haraway, 2003; 2008; Tsing, 2012). We might attribute this development to the increasingly expanding notion of design and to the adventurous desire to extend design research into new areas of the sociocultural or natural domains. While most of the research projects analyzed in this paper maintain a close affinity to technoscience, they almost univocally depict animals as what American feminist, biologist, and philosopher of science Donna Haraway $(2003 ; 2008)$ has called a companion species. This paper seeks to expand on the concurrent notion of companion species by proposing a category of familiar animals in an urban context that not-quite fits the interspecies dependencies we would attribute to significant others. Or, to be more precise, the precarious potentiality of new relations between animals and humans that raises significant new questions regarding the predominant anthropocentricity in design and design research.

Importantly, these design experiments do not aim to eradicate the human perspective. Rather, it is an attempt to investigate the possibility of a pluralization of perspectives in design by insisting on placing human and animal actors as equally capable of action. Hence, we aim to expand the horizon of how and whom we design with and include into the design process. As an exploration of what decentralization of the human perspectives in design might entail, we explore the notion of foray' through our current design research project Urban Animals and Us (UA $\& U s)$. The term is appropriated from experimental biologist Jacob von Uexküll and developed in the paper as an investigative approach that combines tools and formats from the field of co-design with a speculative approach by which design prototypes are used as means to explore worlds that lie beyond our direct access.

In the paper we first give an overview over animals and experimental design research that we then relate and expand to the notion of not-quite companion species. We continue by describing how the $U A \& U s$ project accesses speculation along with specific co-design tools as a methodological bricolage. In the case section of the paper, we expand the theoretical underpinnings by providing evidence of the design experiments in the field. Here, our designerly research agenda has been to conceptualize the neighborhood in the Danish city of Elsinore as an urban ecology that we co-inhabit with many different species. Through a set of three practical design experimentations developed in close dialogue with four collaborators, we explore questions such as, 
how do we take a not-quite companion species perspective into account? And, in the forming of new interspecies behaviors, how do we foster relationships that enable communication among species? We continue by giving a more detailed description of the first experiment as an unfolding of a foray into other relations between humans and birds. In the final section we conclude by relating the case to a larger set of issues of ecological changes in order to show how attempts to make a pluralization of perspectives can provide a productive alternative starting point for design.

\section{ANIMALS \& EXPERIMENTAL DESIGN RESEARCH}

Pigs and other domesticated animals make up a surprisingly ubiquitous source of material in the industrialized production of designed goods, whereas animals in general seem to occupy a limited space in design discourse.

In the book project PIG 05049, Dutch designer Christien Meindertsma makes this abundantly clear by tracing the corporal remains of pig no. 05049 from a pig farm in Rotterdam to no less than 185 products ranging from food to porcelain and ammunition ${ }^{2}$.

Similarly, a mapping of the historical role and significance attributed to animals in design research could undoubtedly be of significant value, but lies beyond the scope of this paper. In the following section we will instead attempt to position UA \& Us in relation to a disciplinary initiative and two experimental research projects in order to elucidate shared focal points of what perhaps could be viewed as a new disciplinary interest in animals in the making.

\section{ANIMAL MANIFESTO}

In 2011, a group of researchers from the human-computer interaction community $(\mathrm{HCl})$ published an animal-computer interaction (ACI) manifesto in the ACM Interactions journal (Mancini, 2011). Some of the central questions for a new research agenda proposed in the manifesto are: (i) how do we involve animals in a design process, and (ii) how can we develop a user-centered design approach towards animals? Other questions are: (iii) how can we elicit requirements from nonhuman users, and (iv) with what criteria do we evaluate the technologies we develop for animals?

To a large extent, these questions are mirrored by the interests put forth in UA \& Us. There are, however, differences. Perhaps this is most evident in the questions of evaluation of technologies developed for animals and the categorization of non-human animals as "users". The objective here seems to be in line with the main strain of human-computer interaction research, with the primary difference being

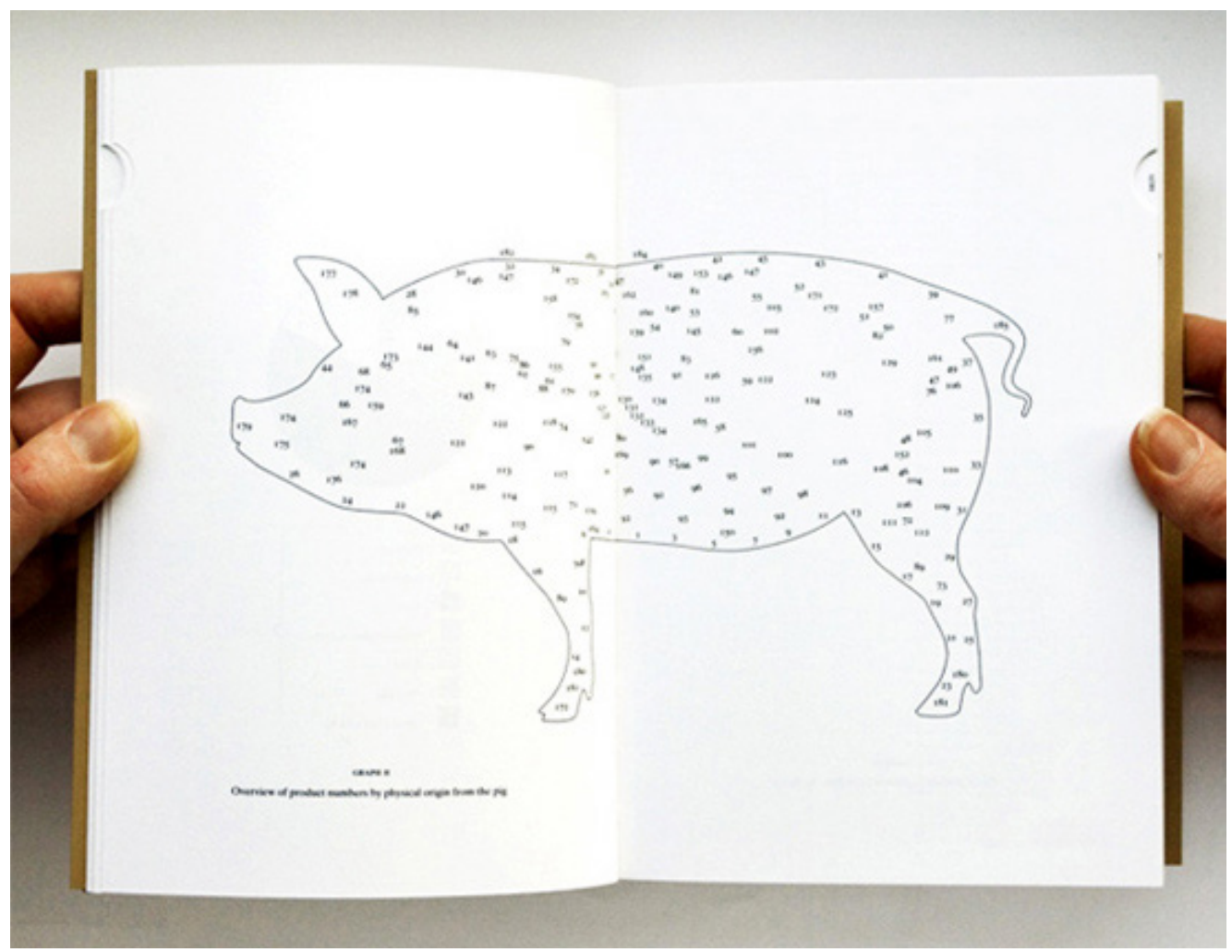

Figure 1: Christien

Meindertsma's PIG 05049 is mapping the animal through skin, bones, meat, organs, blood, fat, brains, hoofs, hair, and tail becoming human-centred products. 
the substitution of humans with animals. The central mechanisms of a teleological design protocol are continued, albeit now with a new series of challenges pertaining to difficulties in gaining access to the requirements seen from an animal perspective. In a road map presented on their blog $^{3}$, the $\mathrm{ACl}$ special interest group, among other things, suggests that collaboration with other established science disciplines such as ethology, behavioral medicine, and animal psychology could be one way of gaining knowledge about animals. While it certainly seems like a sound projection of a feasible development, it also falls inside the well-trodden disciplinary bounds of $\mathrm{HCl}$ research.

We make a point of this, because it marks a divergence with respect to the experimental approach we propose in UA \& Us. The gulls and crows, as significant others, are not perceived as non-human users for which we have located a specific problem to be met through means of design and technology. Rather, they are primarily co-constituents of a common urban context surrounding the nursing home Grønnehaven, with the potentiality of entering into new relations through designed interactions based on imaginative speculation rather than science facts.

\section{NETWORKED RELATIONS \& MULTISPECIES ETHNOGRAPHY}

At the University of Wellington in New Zealand, Dr. Anne Galloway currently leads a three-year research project entitled Counting Sheep: NZ Merino in an Internet of Things. As the title suggest, this project emphasizes the animal - the Merino sheep - in relation to emergent cultural and technological changes: "Using NZ merino as our case study, we will work with farmers, industry and government to imagine possible technological and social futures for the production and consumption of merino sheep and products." ${ }^{4}$

The aim of the project is to enhance public understanding and participation in new technologies through the intermediary of design research and especially the engagement in the production of future visions of agricultural technologies.

What makes the research project proposition interesting with regards to the position of the animal, is that it first of all represents a multiplicity of actors and events: "high country stations, sale yards, A\&P shows, shearing competitions, dog trials, offices and labs to talk with breeders, growers, shearers, wool sorters, scientists, industry representatives, government policy makers and others" (ibid.). The Merino sheep, in other words, seems principally to be constituted by its networked properties. This is not to say that the project doesn't take a concerted interest in the actual sheep, which is evident from the project's accompanying research blog (http:// www.designculturelab.org), but rather that it relies on an epistemological approach that foregrounds multispecies- and multi-sited ethnography (Kirksey 2010) in accordance with an actor-network theory schema. An approach that also manifests the sheep as companion species as well as products of the evolution of naturecultures (Haraway 2003), something we will return to in the next section. UA \& Us could be conceived of in a similar manner as it certainly involves networked relations between seniors, gulls, computers, and a nursing home institution - it also marks a difference in degree, as it puts greater emphasis on context (the urban), and the ontological contingencies of the objects and animals involved. These qualities are more approximated to those found in the next project we will describe.

\section{CO-HABITATION IN URBAN CONTEXTS}

Amphibious Architecture is a floating installation in New York's East River ${ }^{5}$ that collects information on pollution levels and the presence of fish in the river, and it enables public inquiry into these matters via text message. Glowing lights on the surface relegate the interaction and activities to below the surface in real time. As David Benjamin from architectural firm The Living explains, one of the most important results stemming from the interaction was that "when people decide to ask a question about their environment through our SMS system the river becomes a contact on their phone. And when people start talking in a smart way to objects and public places in the city, all kinds of new things become possible." 6

The contingent potentiality of new things to come as a consequence of having things (such as rivers) and animals (such as herrings) on "speed-dial" comes very close to the ambitions of UA \& Us. What is shared by these objects and animals is proximity and the co-habitation of an urban context. Amphibious Architecture enables us to enter into new types of relations with objects (including animals) and potentially over time make these entities significant others. The objects and animals (e.g. rivers, gulls or herrings) of interest belong to a different category then the pigs and sheep of the previous projects, in that they historically and biologically share less interrelations with humans. They belong to a sphere one step further removed from humans, 
and thus - following Donna Haraway - could be designated as not-quite companion species. This notion will be elaborated further in the follow section.

To briefly sum up the above "triangulation" of $U A$ \& Us among other experimental research projects with a vested interest in animals, we might contend that they combine the focus of animals with interactive technology as well as an orientation towards collaborative, anthropological, and user-centered design methodologies. The notable exception from the latter being Amphibious Architecture that more closely resembles an art installation than a process oriented design project. What furthermore can be drawn from the above comparisons is the importance of (i) context and proximity in Amphibious Architecture, (ii) the correlation between ethnographic informed collaborative methods and design speculation in Counting Sheep: NZ Merino in an Internet of Things, and finally (iii) the insistence on a formalized research agenda that places animals center-stage as promoted by $\mathrm{ACl}$.

\section{DESIGN EXPERIMENTS WITH NOT-QUITE COM- PANION SPECIES}

In this section we will identify the theoretical cornerstones for the notion of not-quite companion species and subsequently provide a provisional framework for the methodological underpinnings of $U A \& U s$.

In 2003, Donna Haraway published a small book called The Companion Species manifesto - dogs, people and significant otherness. For Haraway - famous for her "Cyborg Manifesto" (Haraway, $1985)$ - the notion of a companion species denotes a more extensive category than companion animal to include entities like "rice, bees, tulips and intestinal flora, all of whom make life for humans what it is - and vice versa" (Haraway 2003, p. 15). But the notion should also be understood as (i) something within the history of evolutionary biology, yet simultaneously mechanistic and textual; (ii) species as a philosophical category by which we define difference; (iii) the complex juxtaposition of the material and the semiotic; and (iv) the impurity of conflation between scat and refined cultural commodities. The last point is driven home by Haraway's specific interest in dogs, from poop-scooping to breeding. In sum, Haraway's manifesto aims to implode the hygienic categories of nature and culture into the

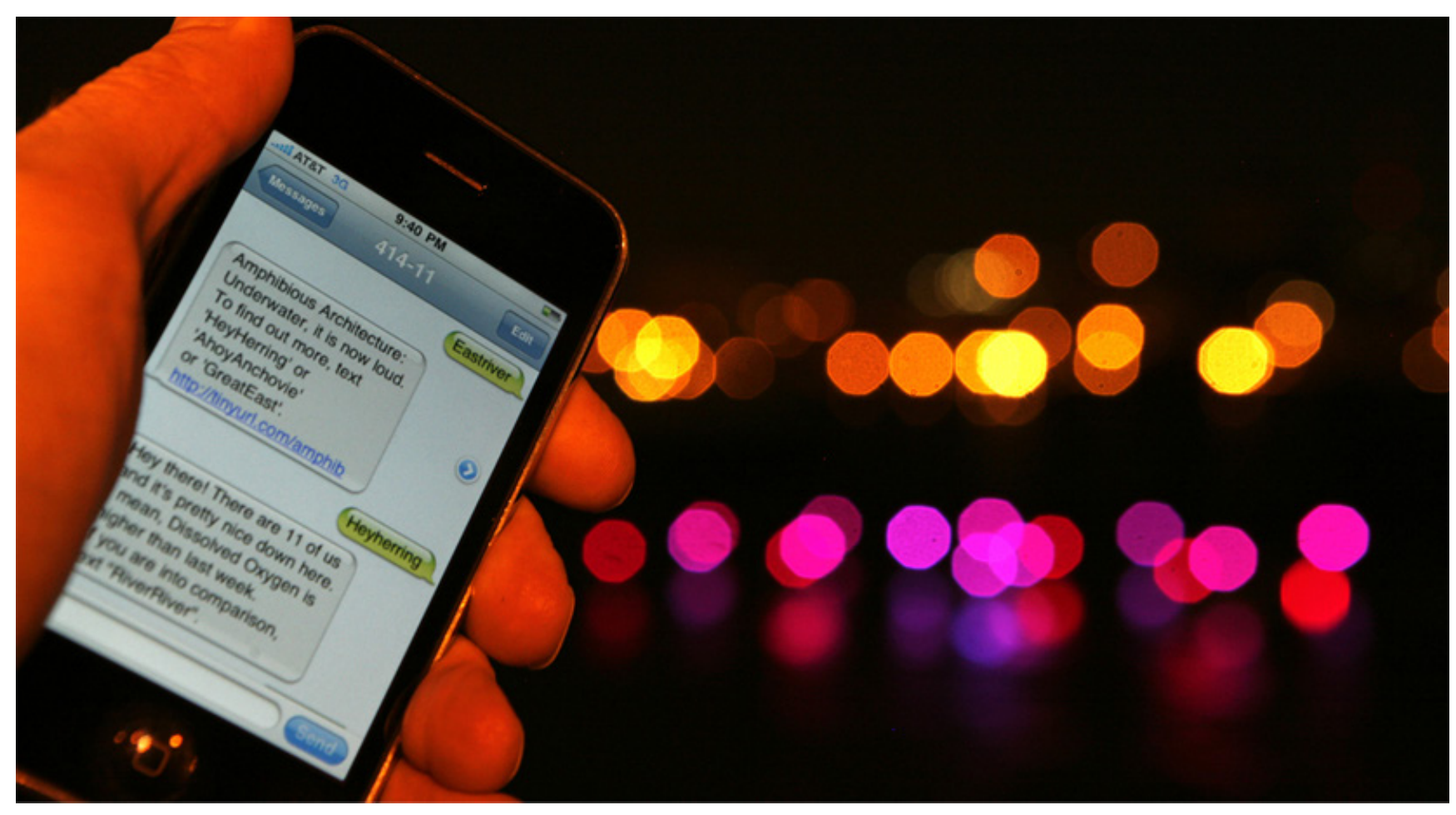

Figure 2: An SMS received from New York's East River fish describing how many fish they are and pollution levels through a floating installation. 
far more complex and messy "choreography of ontologies" - or naturecultures - and the companion species epitomize this change ${ }^{7}$.

Companion species, like Haraway's dogs or Merino sheep in New Zealand, can be characterized by their long historical interspecies relationship with humans. Recently, anthropologist Anna Tsing (2012) has argued for the extension of companion species to mushrooms. This indeed broadens the context by a huge margin, and suddenly our claim to perceive gulls, crows, and even rats as companion species seems a lot less radical as they, after all, still belong to the kingdom Animalia. But it also places the urban animals we're interested in nicely between the close proximity of the human habitat (e.g. dogs or intestinal flora) and the wider (and wilder) ecologies of fungi, of which mushrooms - according to Tsing - enjoy a symbiotic relationship with humans (Tsing 2012 , p. 142) that extends far beyond the cultivated landscape.

This brings us to a simple yet crucial aspect of companion species: namely that it always requires a minimum of two species to enter into relation (Haraway 2002, p. 12). For all the examples given here, including our own, the "significant other" is viewed from the position of the human. When we propose the prefix "not-quite" to companion species, it is merely to emphasize a category of animals with more opportunistic, weak and - perhaps most importantly - precarious interspecies relations with humans, much in the same way as herring in New York's East river. They are all animals that most of us find difficult to categorize as companions, even though we co-inhabit the same (urban) space.

Haraway makes a compelling argument for the primacy of the relations over relata when she writes:

Dogs are about the inescapable, contradictory story of relationships - co-constitutive relationships in which none of the partners pre-exist the relating, and the relating is never once and for all (ibid.)

To this we might contend that not-quite companion species with their precarious, could-be relationships should be defined just as much by the shared context in which relations are potential, yet not always given.

\section{SPECULATION AS PREMISE FOR EXPERIMENTATION}

The experimental nature of the project does not follow a more traditional design protocol. I.e. there has not been a successive identification of problems followed by optimum solutions nor reliance on firm epistemological grounds (e.g. substantive knowledge of animal behavior and psychology). Instead, since the inception of the project, the potential relations between crows, seniors, gulls and nursing home staff as not-quite companion species, are merely figments of our imagination, or at its best precarious. Hence, speculation combined with adapted methods from co-design has become the experimental modus operandi of the project.

Speculation has a rich and varied history in both design and other fields and disciplines. In ethology a prominent precursor to a speculative approach in understanding animal behavior is found in the work by Baltic German biologist Jacob Johan Uexküll (1867-1944). Uexküll is probably most renowned for his idea of Umwelt: the perceptual life-world of living beings (Uexküll 2010). For him, Umwelt is always a world or environment for someone. The only way we can attempt to access this subjective position is ultimately through informed speculation or a foray [Streifzüge] into a world experienced by the subject. Thus, for example, Uexküll would analyze ticks, sea urchins or bees informed by knowledge based on observations and behavioral experiments, but to leap from facts to the subjective experience he would have to utilize speculation to depict, for instance, the Umwelt seen by a bee or in our case a gull.

In his recent book Alien Phenomenology, American media philosopher lan Bogost links Uexküll's "plurality of incommensurable yet strangely overlapping worlds" (Bryant, 2010) with the notion of carpentry. For Bogost, carpentry combines the ordinary meaning of woodcraft with the idea of constructing things that do philosophy:

Blending these two notions, carpentry entails making things that explain how things make their world. Like scientific experiments or engineering prototypes, the stuffs produced by carpentry are not mere accidents, waypoints on the way to something else. Instead, they are themselves earnest entries into philosophical discourse (Bogost 2012, p. 93)

Bogost diligently points to a methodology that at least partially resembles what we aspire to with $U A \&$ Us. With the difference that we are more 
interested in how not-quite companion species make up each other's worlds and would rather contribute to a design - instead of a philosophical - discourse.

A foray into the worlds of seagulls and seniors entails a mode of experimentation, which is potentially transformed through the deployment of speculative prototypes that may or may not actualize new interspecies relations. But, much in the same way as Uexküll's scientific observations and behavioral experiments informed his speculation on the subjective world of bees, so is the encounter with the various actors structured by methods and tools from co-design.

\section{METHODOLOGICAL BRICOLAGE}

We have until now described $U A \& U s$ as an experimental project, and more specifically as a foray into the uncharted territory of human-animal relations by means of co-design tools and speculative prototypes. In the context of the overall project, this paper expounds a foray to account for an exploratory approach that joins the eventual "becoming with" (Haraway, 2003; 2008) of a potential companion species - with speculation as a way to operationalize that which has not yet been actualized.

As a theoretical framing, a foray into not-quite companion species critically addresses the prevalent anthropocentricity of design research by exploring the relations between species as a potential to enter into (other) interspecies perspectives of the world, rather than, designing for animals.

Methodologically, the extension of co-design tools and methods to animals is further governed by a different line of design research in the tradition of experimentation with the interpretive ambiguity of the multivalent relations between people and design artefacts (Gaver, Beaver, and Benford, 2003) ${ }^{8}$. In UA \& Us the experimental prototypes are not designed to be ambiguous in themselves, but rather to prompt people to imagine new kinds of relationships with animals and invite them to collaboratively explore the possibility of these relationships through design events (Halse, Brandt, Clark, \& Binder, 2010, p. 71). Hence, speculation becomes a premise for the design experimentation. Albeit, speculation here is less preoccupied with the interpretative ambiguity of relationships (Gaver et al., 2003) and more directed towards the ontological possibility of co-constructively sparking new relations into being.
CASE: URBAN ANIMALS AND US

In the section below, we will describe design intentions, collaborative set-up, as well as the materialization of the design experiments that unfolds. Guided by the question of how we materially nurture relationships that enable communication and new relations among species, we explore different ways in which to present and involve a multiplicity of species in the urban heterogeneity. The aim has been to let "them" intervene, as much as "we" intervene in each other's everyday. In each experiment a experimental prototype has been constructed to further explore the field of cross-species communication.

\section{Stakeholders and collaborations}

The design experiments in UA \& Us are accommodated and deployed at the retirement home Grønnehaven. The practical experimentation and final designs have been developed in close dialogue between the authors, the local municipality's volunteer-center, and an architect-duo in an ongoing collaborative process. Finally, a small interaction design bureau has come to aid us with technical and digital issues. Nonetheless, the main relationships discussed throughout this paper are more centered on the experiments where the different actors come together in new ways - with the focus on the retirement home Grønnehaven, its seniors and the local animals in the urban milieu of Elsinore.

\section{Design set up and process}

Situating the project as a speculative co-design means that we have intentionally tried an alternative to a top-down organization. UA \& Us has been carried out in an open events format (Halse et al., 2010; Mazé \& Redström, 2008). An event involves many participants covering many different tasks, such as presentations, collaborative writing, material experimentation, and analysis in an open-ended format. Another important issue is that an event extends in time. More specifically to our project, this can be seen in the joint writings of a blog, the tinkering with Arduino boards and Raspberry computers, field visits with hunters and ornithologists, as well as the many hours spent in the local wood-workshop. Nonetheless, the design concepts were initially developed by the design researchers as sketches. Later, the hand-drawn sketches where presented to the stakeholders and collaborators who criticized, evolved and analyzed the initial concepts and drawings.

At this point, it is important for us to highlight that the event driven process is in $U A \& U s$ is then formed into three more specific experiments. This setup entails, as further described in a following 


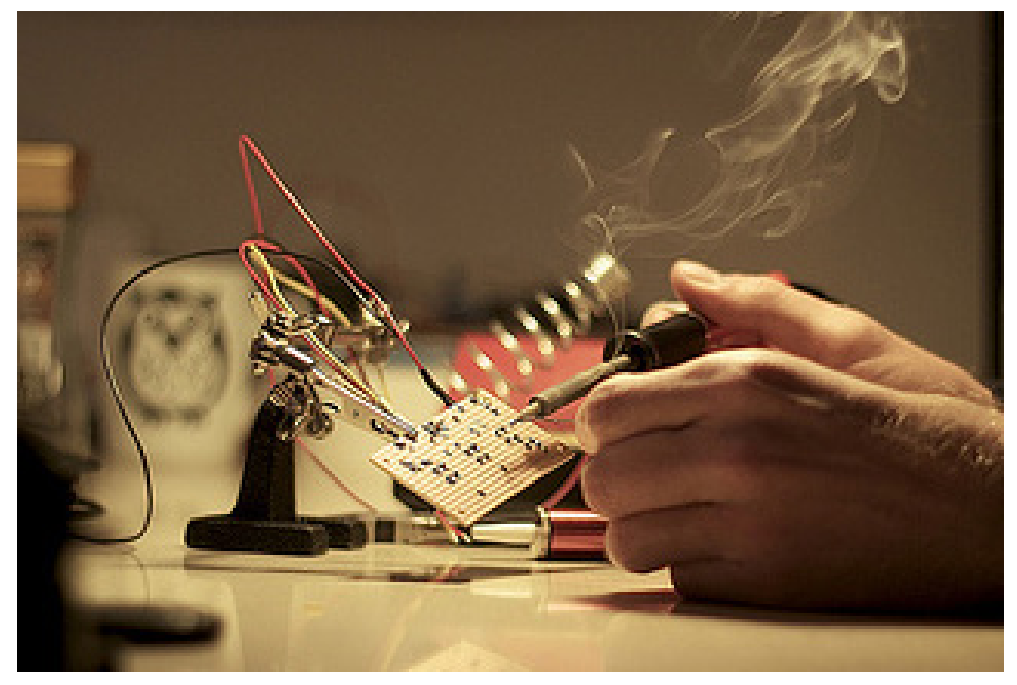

Figure 3: Circuit soldering activities later to be used in the final experiment PhotoTwin.

section, an open invitation to the residents and employees of Grønnehaven to participate in the experiments where we collaboratively unfold and make sense of the speculative prototypes and the potential new interspecies relations. As design researchers, we have set up a loose structure for the gatherings, but left the program open to evolve along the way. Furthermore we have applied a micro-material perspective (Agger, 2009). Following Agger, this perspective helps broaden the understanding of the role of things and tangible working materials in co-design, but also provides practical concepts for engagement. Design materials are described here both in terms of what is brought into a co-design situation to be explored collaboratively as well as the outcome destined for the continuous design process. Importantly, the design materials need to be situated and appropriated to the specific situation to allow for a collaborative exploration.

\section{Three design experiments}

The three different experiments all bridge the concern of taking the nonhuman worlds seriously. Compared to hunting technologies where the relationship is made up of humans using tools to act upon non-humans as a top down relation, UA \& Us aims to construct technologies of reciprocity. Each of the three experiments explores a specific notion of reciprocity that we further describe below.

We finally continue to give one more in-depth example in relation to the first experiment of what emerges and unfolds during one of the several workshops held.

1. The first experiment, $A$ Birds View Perspective is exploring the notion of exchanges between the different actors in our shared urban space. For the experiment, our Bogostian carpentry skills where used to develop the BirdCam, meant to allow the

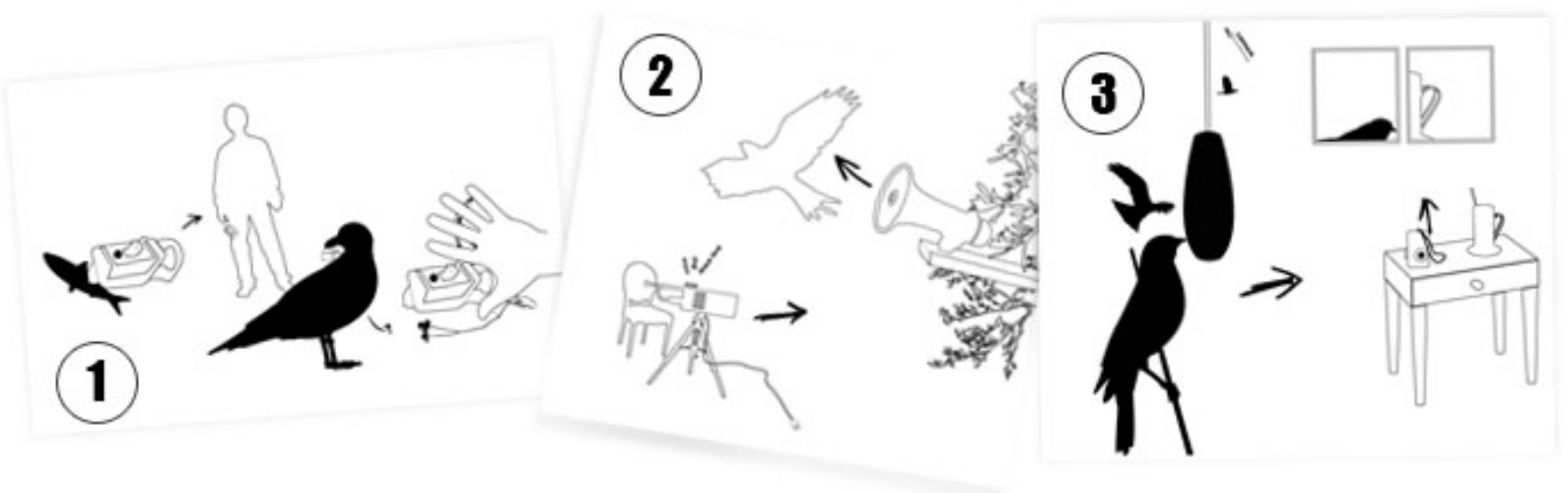


Figure 5: The BirdCam attached to a piece of bread in the grass in front of Grønnehaven retirement home. Haraway $(2008$, p. 17) observantly reminds us, that the word companion comes from the Latin cum panis, or with bread.

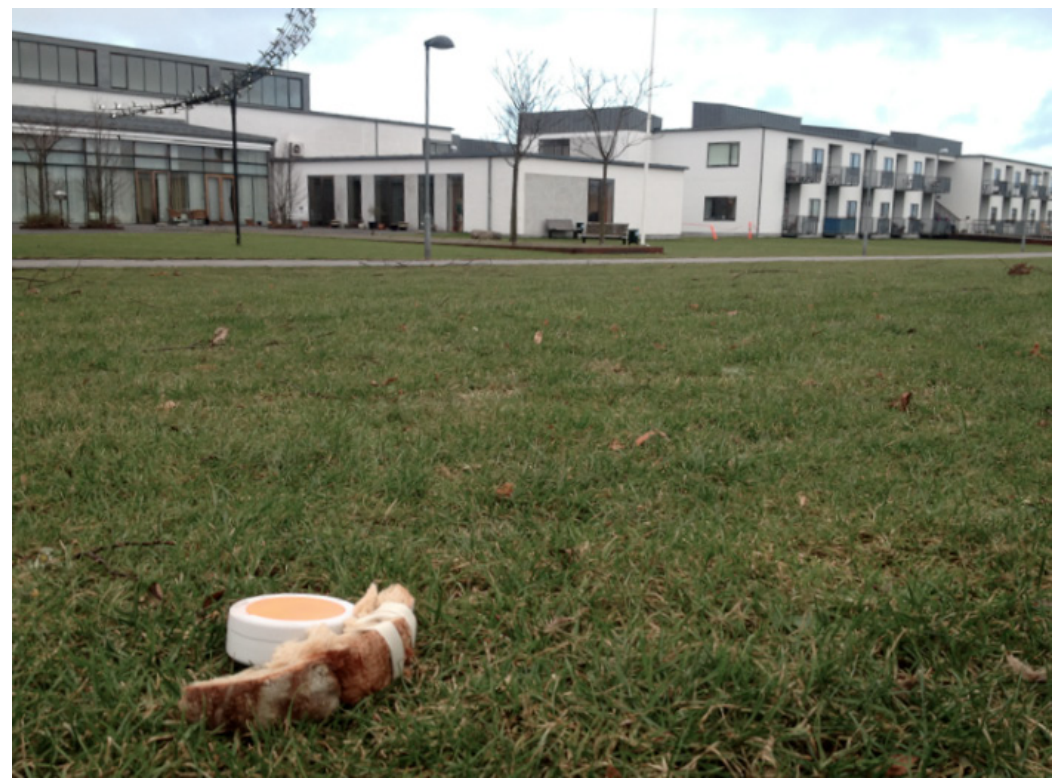

birds themselves to film and be in control of a video camera with the intention to literally give a birds'seye view of the local area.

The BirdCam is a small device made of off-the-shelf components including an inexpensive spy video camera that one can attach bird food to. The weight of the object means that not any animal can pick it up. Instead it is meant to be used by the strong, large black-backed gulls outside Grønnehaven. Set up as an exchange, the gulls might film the local milieu from their perspective, but only if the seniors set up the exchange (the BirdCams) with the food. Put simply, the BirdCam can only work its wonder if both actors put their effort in. Without attaching the food, it offers little in exchange for the gulls, and

Figure 6: The BirdFlute is designed to blend in with the Grønnehaven deco where it is placed in one of the shared spaces over-looking the outdoor speaker at Grønnehaven.

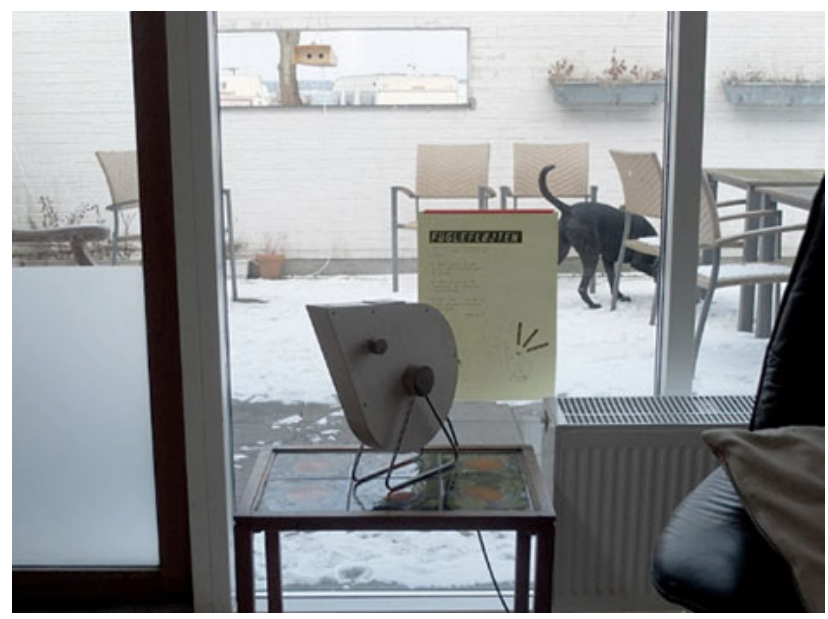

without the gulls the BirdCam is nothing more than a small and strange-looking device to the seniors. Its agency depends on joint effort.

2. The second experiment Talk-in-To deals with communication as translations between species. We know that (some) animals can understand us and follow our demands. In the bird-human history this is typically recognizable in the parrot that learns to mimic human speech. Parrots are social creatures, so it may seem advantageous from a survival standpoint to learn the language of their new flock - the humans in their home. However, in the Talk-inTo experiment, instead of letting the parrot mimic us, the sounds made by humans are translated into non-human messages through the BirdFlute.

The BirdFlute uses similar technology as hunters for calling in prey - with the obvious difference that a conventional duck call is used for the purpose of luring in the bird in order to kill it. When blowing into the flute-like instrument, the outgoing sound mimics a sound from another species, like a crow.

By switching a knob on the instrument, one can change the soundscape from crow to a magpie or blackbird. The sound created by the flute is then transmitted via a digital network to a small speaker placed outside the retirement home Grønnehaven. Pressing one of the three different keys causes a change of animal call, allowing the seniors to enact and intervene in unexplored spaces of interspecies communication. 


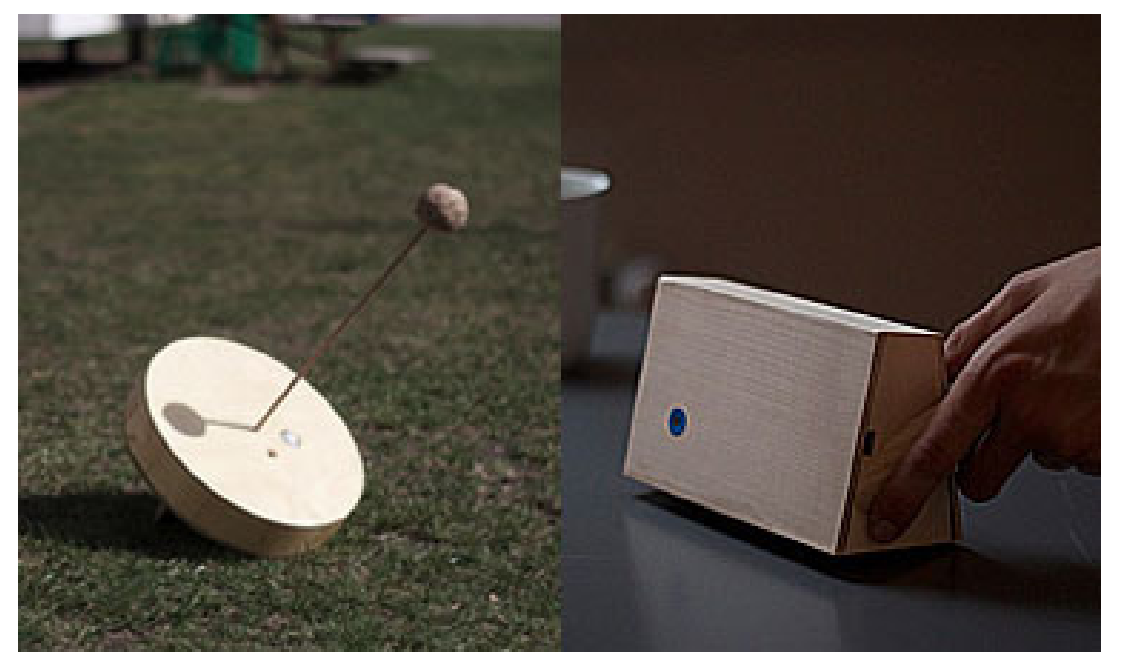

Figure 7: The PhotoTwins outdoor and indoor camera devices.

The sounds are a selection of different bird calls that have been recorded and interpreted into different functional signals on a shared Internet community used by ornithologists. Since no "bird call-experts" have been involved in the experiment, the translated digital sounds are far from stable translations. Instead we have to rely on Grønnehaven's residents to consent to explore other ways of communicating, and perhaps to make beginners' "zoo-grammar" mistakes.

\section{The final experiment InterFed explores power} relationships. Through the device PhotoTwin the experiment speculates on how to establish more equal interspecies relationships. Its closest resemblance might be that of a camera trap, often used to scout for game or for capturing wild animals on film when researchers are not present. Instead of being disguised and camouflaged to capture an animal in the

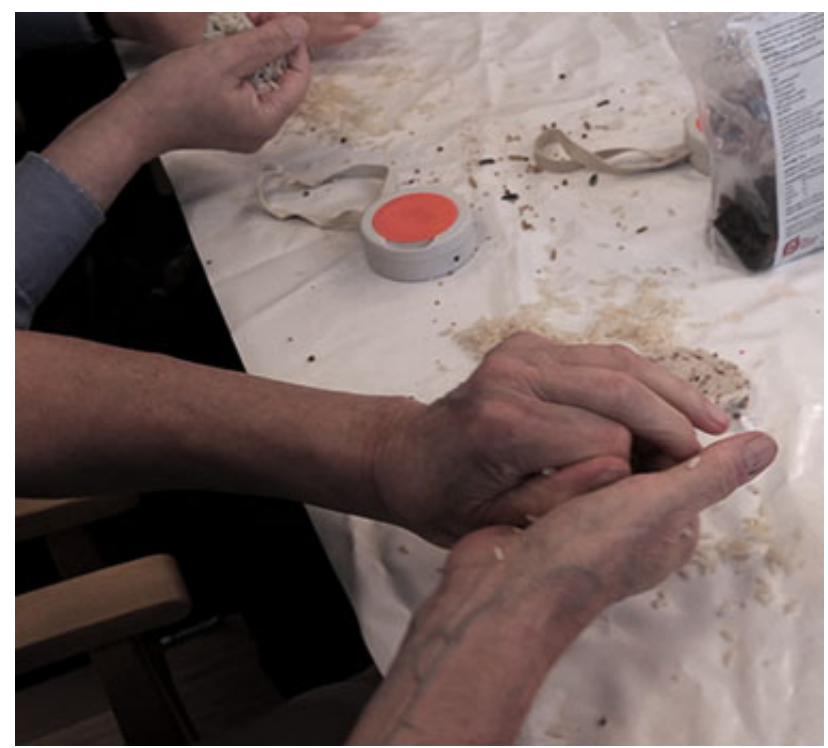

midst of the forest, the PhotoTwin traps both animal and human everyday practices via photographs on attempted equal grounds.

The PhotoTwin consists of two digital camera devices, one being located outdoors and one inside the retirement home. The outdoor camera device is triggered when birds are pecking on the replaceable shutter releaser made out of bird-food. Simultaneously, two different photos are taken, one photo of the birds' outdoor practices and one of the seniors' indoor practices. The two photos are then displayed side by side on a portable screen in the retirement home. The fact that it is the action of the bird - as a true nature photographer - that triggers the shutter release is a way to intentionally give active agency that allow the birds to intervene and affect the "great indoors".

\section{A foray: the unfolding of the experiment}

Before we further unfold what came into being during the first experiment we'd briefly like to mention that Talk-in-To and InterFed are deployed over a longer time at Grønnehaven, leaving the residents to explore the instruments at their leisure. By contrast, the workshop approach adopted for the first experiment, which we describe below, is very compressed in terms of time and dependent on both human and non-humans to show up.

We are in total 12 people that have gathered around the table: eight residents and two employees from Grønnehaven, the two authors and one participant from the local Volunteer center. The participants have been invited to a workshop for making bird food for the vaguely described "bird-cams". During the three hour-long workshop we make a selection

Figure 8: The different materials are kneaded together and shaped to fit the BirdCams. 
Figure 9: The BirdCams have been placed outdoors during our first attempts to get a birds view perspective and are followed with curiosity by some of the participating seniors.

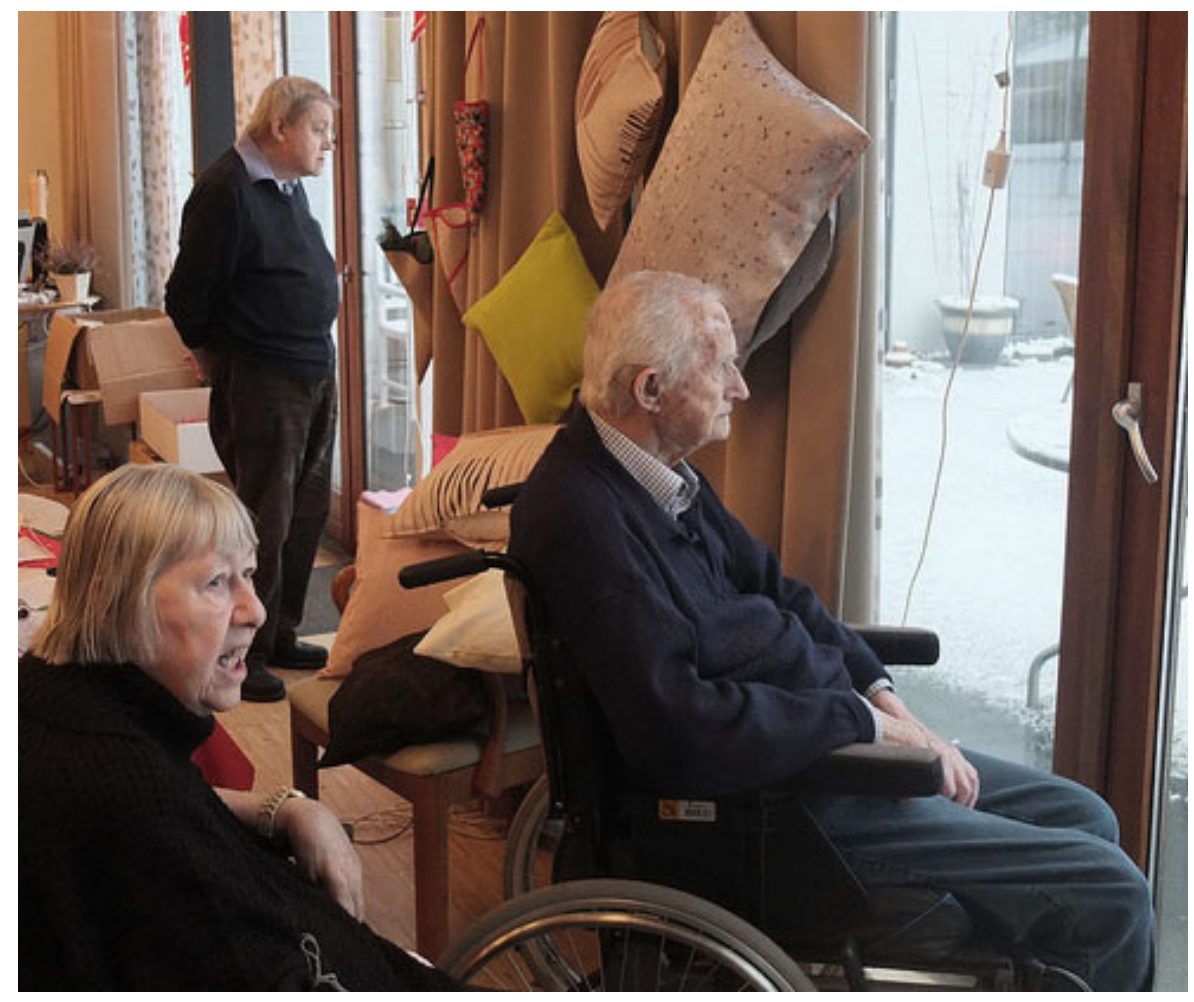

of bird food with included ingredients such as raw fish, seeds and food-waste from the retirement home.

While kneading together materials like fish, flour, coconut oil and bacon to tempt the carnivores and scavenging birds, there are no direct questions about why we want to make bird food for the less favored birds. However, the animals are discussed as "rather opportunistic" and ever present. One of the residents shares her memories:

- "I'll never forget the summer when we were grilling, and a huge gull landed right on the grill, and stole a beefsteak!" While one of the staff raises her issues:

- "I cannot believe I am here making bird food. I cannot stand birds!" She continues and explains how she barely dares to venture outside the retirement home when there are to many birds gathered on the lawn. Still, some of the participants are keener on birds:

- "I live on the ground floor, and I feed the birds every day." To which someone quickly airs worries of other scavenging animals:

- "How about rats then?"

It is hardly a symbiotic relationship towards the species we are now trying to create a food feast for. During the session the slightly troublesome relationship with the birds seems to be overshadowed by the making of the bird food. Getting our hands greasy together and making the bird food takes up the most of the rest of the conversation. If we take a micro-material perspective by paying attention to the physical material, we can se that they function as a communication device of inclusion both for the seniors and also later for the urban birds enrolled in the experiment.

However, it is not until towards the end of the day, when five bird-cams are released into the urban surroundings, that we end up getting closer to our not-quite companion species. Due to the stormy weather, the senior participants watch the spectacle of releasing the cameras from the safe indoors. There is a nervous anticipation in the room since we cannot rely on the birds to show up, not to mention picking up the cameras. The BirdCams are placed on the lawn outside the common area at Grønnehaven where lots of terns are circling around. Since the BirdCams are too heavy for terns, we are all awaiting the arrival of the larger black-backed gulls that can carry the weight of them. After about 20 minutes the lawn has gathered a large selection of birds. During the wait, some of the participants of the event are spending their time guessing what birds have arrived:

- "What is the black one? It is not a seagull. Maybe it is a blackbird?"

$$
\text { - "Yes, or maybe it is a crow, I see them }
$$

here. Or a magpie?" 
Among about fifteen terns, two of the anticipated black-backed gulls finally show up:

- "Look, look! Now they are here. Yes, it is one of the big sea gulls." After a short while one of the members of staff shouts out enthusiastically:

- "It has picked up one of the BirdCams!"

leading to spontaneous applause in the room.

- “Oh no, it dropped it. It lifted it over the pathway. Did you see that? - Oh, it is there again. It got it. Yeah!"

When the whole event ends, two out of the five birdcams have been taken on a small flight. Outside, light has become dark, we gather our things and finish the workshop with the advice from some of the participants to make the BirdCams a little bit lighter in terms of weight for our next session.

\section{REFLECTIONS \& DISCUSSION}

In some senses the experiment (A Birds View Perspective) failed with regards to the intention of getting a bird to fly off with the camera and film the local area. The film made by the birds only contains seconds depicting a blurry film of snow. However, we are not evaluating a prototype - we are "assembled in a foray". So allow us to linger for a moment upon the notion of interspecies exchanges during the experiment: as we, the seniors, and the opportunistic animals where brought into contact through the event of the experiment, mutual surprises occurred. After the experiment the opportunistic birds where not perceived as quite the same animals as before, either by the seniors or us.

Even though we only got a blurry film to show - or what Bogost might refer to as a carpentry result: an outcome of the things that explain how things make their world - they have, in the language of Bruno Latour, become "things". By becoming a thing, we mean a gathering, or a matter of debate (Latour, 2008 , p. 119). Things, as explained by Latour, are unfairly accused of being static and stable (ibid.). However, the gulls are showing us precisely this, they are as unstable as can be, doing things we cannot expect.

At the same time, the birds are as much part of the event as anyone else. We have to rely on them turning up, as we have to rely on the cheap cameras to work, as on the seniors to engage in making the bird food. Importantly, our attempt to speculate, referencing Uexküll, on the subjective notion of a gull's Umwelt pluralizes the perspectives. It is neither a gull's perspective, nor our perspective - it is another, a new perspective. And under these conditions, we all take risks, and through the experiment we allow others, of all shapes and sizes, to object to the stories we tell, to intervene in our processes as we intervene in theirs - in the hope of learning what matters to humans and non-humans alike.

Related to a larger set of discussions, such as environmental issues and ecological changes, it is argued that we need to take account of ozone holes, coral reefs, garbage heaps, and a long list of other issues (Bryant, 2010; Latour, 2004). This requires us to question not just arrangements between humans, but to open up to an entirely different universe - a multiverse - of actors. UA \& Us is obviously a first small step, a micro exploration, into the almost incomprehensibly large issue of how species can co-exist under the strain of increased ecological pressure. Urban spaces, as the areas of Elsinore surrounding Grønnehaven, constitutes a scale and level of multispecies complexity that has enabled us to explore the potentiality of new relations.

At the level of disciplinary discourse, the experiments in UA \& Us gives an example of how we can reframe the hegemonic centrality of the human in the midst, i.e., the overriding and pervasive anthropocentricity of design and design research. The design experiments are not designing for animals, but neither are they designed for the seniors. Instead, it is weaving things and practices around us together, to allow for a slippage in perspectives from a designing for to a designing as a means to becoming with that is the central aim of this project. If it is "about" anything it is about finding ways of engaging and enacting worlds, of making room for the re-enchantment of reality (Bennett 2001). Easy to say, of course, but so much harder to do, to enact, to make real.

The experiments are neither an attempt to denigrate humans nor human collectives - in fact far from it. It is rather an experimental setting for the exploration of a foray into an anthro-de-centrifying ${ }^{9}$ stance in design research that places humans, animals, institutions, technologies, design artefacts, etc., on equal ontological footing. The underlying hypothesis here is this: The de-centering of human mastery opens a space, a potentiality, or in Deleuzian terms, the possible actualization of a multiplicity of perspectives (Deleuze, 1987). Creating opportunities to experience new relations, in this case primarily between birds and humans, can allow us to cautiously sketch out different modes of being in a shared world. That is not only sketching relations between humans and non-humans, but rather the ecology between things and beings. 


\section{CONCLUSION}

In this paper we have argued for a design experimentation premised on a de-centering of the human perspective as an approach that seeks to place a multiplicity of actors as equally capable of action. Our focus has been on animals and more specifically birds with which we share the urban context.

While birds - and other urban animals - already have partial relations with humans, we have argued that Donna Haraway's notion of companion species is too narrow or unspecific to accommodate the kind of interspecies relations we might share. To remedy this we have introduced the notion of not-quite companion species.

We began by giving an account of other contemporary design research projects with a specific interest in animals as companion species. While they maintain different objectives, we conclude that they also share a great deal in terms of their approach to explorations of relations between humans and animals. None of them, however, shares the explicit interest in the de-centering of the human position that we are interested in here.

Informed by our ongoing research project $U A \& U S$ taking place in the city of Elsinore, we have provided a theoretical foundation for a methodological approach with the notion of foray. Inspired by biologist Jacob von Uexküll's use of foray we have adapted the notion to combine elements from two otherwise separate approaches, respectively co-design and speculation prototypes, to form speculative co-design. We have furthermore argued for the necessity of providing a provisional framework that combines co-design tools and speculation to accommodate the new challenges raised by insisting on the univocal focus on potential relations between disparate entities such as humans and birds.

Finally, the tentative conceptual renderings in this paper need to be further assessed, as the project progresses. It is important to stress that the paper is written from a quite early point in the development of the project, and thus merits the exploratory qualities of testing a theoretical framework against the first accounts from the design experiments. As the project progresses, we will have to further investigate and clarify what actualized relations of not-quite companion species look like, and to what extent they might affect each other's life-worlds.

\section{ACKNOWLEDGMENTS}

Besides the authors, the Urban Animals and Us project team consists of interaction designer Sebastian Thielke and architect Kalle Jørgensen, who have played an equally important role in bringing this project to fruition. We would like to extend our sincere thanks to all the seniors and staff at Grønnehaven for their candid participation in a project that by most standards seems a little strange. We would especially like to thank section-leader Carsten Illsøe, head of the volunteer center Lene Ljungqvist and senior-volunteer Jørn Knudsen for their enthusiastic support and for opening all the right doors. Last, but not least, we want to thank design researcher Carl DiSalvo for his sharp gaze and inspiring critique in an extended online discussion of the project and research agenda.

\section{NOTES}

1. The title of this paper is, unsurprisingly, meant to resonate with Uexküll's notion of foray, as it mimics the title of his booklet: Foray into the Worlds of Animals and Humans (2010)

2. http://www.designboom.com/design/ christien-meindertsma-pig-05049-book/

3. The authors of the manifesto have since formed a research blog spearheaded by an $\mathrm{ACl}$ special interest group. The members are mainly researchers affiliated with departments of computer science and interactive systems: http://www.open.ac.uk/blogs/ACI/

4. http://www.designculturelab.org/projects/ counting-sheep-project-overview/

5. The installation was developed by the Living Architecture Lab, Columbia University Graduate School of Architecture, Planning and Preservation; the Environment Health Clinic at New York University; and the architectural firm The Living.

6. http://www.wired.co.uk/news/ archive/2011-08/26/amphibious-architecture.

7. Haraway's work in this area is echoed by other prominent scholars, perhaps most notably Bruno Latour in his critique of the "modern constitution" and its effect on the global environment. See Latour: We Have Never Been Modern (1991) and Politics of Nature: How to Bring the Sciences Into Democracy (2004).

8. Gaver et al. develop the idea of "ambiguity as a resource for design" as an antidote to the dominant discourse of usefulness, efficiency and predictability in computer-human interaction ( $\mathrm{HCl}$ ). Ambiguity, on their account, is 
an attribute of the interpretations of artifacts and a quality that produces richer and more personal relationships between people and design artifacts through the active (and pleasurable) engagement in meaning making.

9. Matthew David Segall: http://footnotes2plato. com/2012/08/22/anthrodecentrism-the-genesis-and-meaning-of-a-word/

\section{REFERENCES}

Agger Eriksen, M. (2009). Engaging Design Materials, Formats and Framings in Specific, Situated Co-designing - A MicroMaterial Perspective, 1-10. Retrieved from http://muep.mah. se/handle/2043/14730

Bennett, J. (2001). The Enchantment of Modern Life: Attachments, Crossings, and Ethics. Princeton University Press.

Bennett, J. (2010). Vibrant Matter a political ecology of things. Durham: Duke University Press. Place of Publication: Durham, NC.

Bogost, I. (2012). Alien Phenomenology - or what it's like to be a thing. University of Minnesota Press.

Bryant, L. (2010). The Interior of Objects, from Larval Subjects. Retrieved April 17, 2013, from http://larvalsubjects.wordpress.com/2010/12/16/the-interior-of-objects/

Bryant, L. (2011). The Democracy of Objects. M Publishing, University of Michigan Library.

Bryant, L., Srnicek, N., \& Harman, G. (Eds.). (2011). The Speculative Turn: Continental Materialism and Realism. re.press.

Deleuze, G., \& Guattari, F. (1987). A Thousand Plateaus: Capitalism and Schizophrenia. University of Minnesota Press.

Design Culture Lab. (n.d.). Counting Sheep: Project Overview. Retrieved January 11, 2013, from http://www.designculturelab.org/projects/counting-sheep-project-overview/

Gaver, W., Beaver, J., \& Benford, S. (2003). Ambiguity as a resource for design. $\mathrm{CHI}$ '03 Proceedings of the SIGCHI Conference on Human Factors in Computing Systems, 233240. doi:10.1145/642651.642653

Halse, J., Brandt, E., Clark, B., \& Binder, T. (2010). Rehearsing the Future. The Danish Design School Press.

Haraway, D. (1991). A Cyborg Manifesto: Science, Technology, and Socialist-Feminism in the Late Twentieth Century. Simians, Cyborgs and Women: The Reinvention of Nature (pp. 149-181). Routledge, New York.

Haraway, D. (2003). The Companion Species Manifesto - dogs, people, and significant otherness. Chicago: Prickly Paradigm Press LLC.

Haraway, Donna Jeanne. (2008). When species meet. Posthumanities series, Vol. 4. Minneapolis, Minn.; London: University of Minnesota Press.

Hinchliffe, S., Kearnes, M. B., Degen, M., \& Whatmore, S. (2005). Urban wild things: a cosmopolitical experiment. Environment and Planning D: Society and Space, 23(5), 643-658.
Kirksey, S. E., \& Helmreich, S. (2010). The Emergence of Multispecies Ethnography. Cultural Anthropology, 25(4), 545-576. doi:10.1111/i.1548-1360.2010.01069.x

Latour, B. (2004). Politics of Nature: How to Bring the Sciences into Democracy. Harvard University Press.

Latour, B., \& Yaneva, A. (2008). No Give me a Gun and I will Make All Buildings Move: An ANT's View of Architecture. In R. Geister (Ed.), Explorations in Architecture: Teaching, Design, Research (pp. 80-89). Birkhäuser, Basel.

Law, J. (2004). After Method: Mess in Social Science Research (International Library of Sociology). Routledge; annotated edition.

Lenskjold, T. (Forthcoming). Objects of Speculative design in the formation of publics. STS Encounters.

Mancini, C. (n.d.). Researching the interaction between animals and technology. Retrieved January 11, 2013, from http://www.open.ac.uk/blogs/ACl/

Mancini, C. (2011). Animal-computer interaction. interactions, 18(4), 69. doi:10.1145/1978822.1978836

Mazé, R., \& Redström, J. (2008). Switch! Energy Ecologies in Everyday Life. International Journal of Design, 2(3), 55-70.

Meindertsma, Christien. (2008). PIG 05049: Christien Meindertsma (2nd ed., p. 196). Flocks. Retrieved from http:// www.christienmeindertsma.com/index.php?/projects/ pig-05049/

Segall, M. D. (2012). Anthrodecentrism - the genesis and meaning of a word | Footnotes 2 Plato on WordPress.com. Retrieved January 11, 2013, from http://footnotes2plato.com/2012/08/22/ anthrodecentrism-the-genesis-and-meaning-of-a-word/

Tsing, A. (2012). Unruly Edges: Mushrooms as Companion Species - for Donna Haraway. Environmental Humanities www.environmentalhumanities.org, 1, 141-154. Retrieved from http://environmentalhumanities.org/arch/vol1/ EH1.9.pdf

Uexküll, J. J. von. (2010). A Foray into the Worlds of Animals and Humans: with $A$ Theory of Meaning. University of Minnesota Press (Posthumanities).

Wakeford, N., \& Lury, C. (Eds.). (2012). Inventive Methods: The Happening of the Social (CRESC). Routledge.

\section{CORRESPONDENCE}

Li Jönsson, Royal Danish Academy of Fine Arts, School of Design, Philip de Langes Allé 10, 1435 Copenhagen K, Denmark

E-mail: jo@kadk.dk

Tau Ulv Lenskjold, Royal Danish Academy of Fine Arts, School of Design, Philip de Langes Allé 10, 1435 Copenhagen K, Denmark

E-mail: tul@kadk.dk

Published online 12 January, 2015

ISSN 1749-3463 print/ISSN 1749-3471

DOI: 10.14434/artifact.v3i2.3957

(C) 2015 Artifact 